\title{
Aula de regra de três composta no estágio supervisionado: do trabalho prescrito ao trabalho real
}

Class of three compound rule in the supervised internship: from prescrib work to real work

\author{
Elisângela Bastos de Mélo Espíndola ${ }^{1}$ \\ Aída Maria Pereira de Oliveira ${ }^{2}$
}

\section{Resumo}

Este artigo tem o objetivo de analisar a passagem do trabalho prescrito sobre uma aula de "regra de três composta", por um professor-supervisor de estágio, ao trabalho efetivo de uma estudante-estagiária da licenciatura em matemática. Para tanto, tomamos como referência conceitos básicos da ergonomia cognitiva, tais como aqueles de trabalho, tarefa e atividade. Trata-se de um estudo de caso, desenvolvido durante a vivência de uma disciplina de Estágio Supervisionado, realizado com uma licencianda em matemática com a colaboração de um professor-supervisor de uma escola pública estadual, em Recife-Pernambuco. Destacamos como procedimentos metodológicos a utilização das técnicas de entrevista, videogravação e de autoconfrontação simples. Dentre os resultados do estudo, ressaltamos a (re) interpretação do trabalho experenciado pela estudante-estagiária da preparação da aula sobre o tema "regra de três composta" a sua implementação em sala de aula; advinda de suas reflexões sobre seu trabalho docente, sobretudo, a partir da técnica de autoconfrontação.

Palavras-chave: Estágio supervisionado. Regra de três composta. Ergonomia cognitiva. Autoconfrontação.

\section{Introdução}

Diversos autores, a exemplo de Tardif e Lessard (2007) tem chamado a atenção para a docência como um trabalho. Nesta direção, reconhece-se que a análise do trabalho docente se fundamenta em algumas opções conceituais. Como afirma Tardif e Lessard (2007, p. 47) "não podemos abstrair-nos dessas

\footnotetext{
${ }^{1}$ Doutora em Educação (UFPE) e em Science de I'Éducation (UCBL).Professora do Departamento de Educação da Universidade Federal Rural de Pernambuco, ebmespindola@gmail.com.

${ }^{2}$ Licenciada em Matemática. Professora da rede particular de ensino, aidapereira13@gmail.com.
} 
opções, pois são elas que orientam a análise rumo à descoberta dos elementos considerados importantes e sua ordenação para fins de interpretação". Assim é necessário esclarecer rapidamente quais são as nossas próprias opções.

No presente estudo de caso, tomou-se como referência alguns conceitos da ergonomia cognitiva; levando-se em conta que esta pode ser definida como "uma ciência das atividades do sujeito, isto é do ator enquanto pessoa, em situação de trabalho" (ROGALSKI, 2003, p. 343). Deste ponto de vista, consideramos que o professor de matemática é bem um ator engajado em uma situação de trabalho particular: "aquela de ensinar aos estudantes um dado conteúdo matemático, em um contexto institucional particular: o sistema educativo do país (ou um sub-sistema, mais restrito)" (ROGALSKI, 2003, p. 343).

Nesta direção, durante uma disciplina de Estágio Supervisionado, buscamos dar ênfase ao fato que o professor de matemática (mesmo que em sua formação inicial) é um sujeito que em uma situação de trabalho tem seu próprio sistema de limitações e de recursos, "ele tem tarefas a cumprir (ou um conjunto de tarefas, ou de modo mais amplo: uma missão) que o liga a um prescritor (seu empregador, sua hierarquia) por um contrato parcialmente implícito" (ROGALSKI, 2003, p. 347-348). Desta forma, foi tecido o objetivo deste estudo em analisar a passagem do trabalho prescrito sobre o ensino de "regra de três composta", por um professo-supervisor de estágio, ao trabalho efetivo de uma estudanteestagiária da licenciatura em matemática.

\section{Trabalho, tarefa e atividade}

O que é o trabalho do ponto de vista ergonômico? "É uma atividade finalizada de um homem concreto e socialmente situado" (RABARDEL et al., 1998, p. 13). Classicamente em ergonomia se distingue o trabalho prescrito do trabalho real (efetivo). $O$ conceito de trabalho prescrito remete a tudo o que é antecipadamente definido para ser feito. $O$ conceito de trabalho real remete ao trabalho tal qual ele se realiza. "O trabalho prescrito e o trabalho real são 
analisados notadamente em termos de tarefa e de atividade" (RABARDEL et al., 1998, p. 13). A noção de tarefa, com base em Rogalsky (2003), do lado do prescritor, diferencia-se em tarefa prescrita e tarefa esperada. Enquanto que do lado do realizador da tarefa, ela se distingue em tarefa redefinida e tarefa efetiva.

A tarefa prescrita se refere aos "objetivos e condições explícitas em textos prescritivos" (ROGALSKY, 2003, p. 350). De acordo com Rabardel et al. (1998, p.25) a tarefa prescrita é aquela tal qual é definida e apresentada por aquele que determina sua execução. "Ela visa orientar a atividade definindo os objetivos, as condições e limites de realização, os critérios e valores a respeitar... É em princípio a tarefa que deve ser realizada pelo operador". A tarefa esperada "é o conteúdo real das expectativas do prescritor" (ROGALSKY, 2003, p. 350). Rabardel et al. (1998, p.26) chama a atenção que a tarefa esperada pode não estar de acordo com a tarefa prescrita, na medida em que nem tudo é dito ou confessado claramente pelo prescritor.

No que diz respeito à tarefa redefinida, Rogalski (2003) atribui à representação da tarefa que o sujeito tem desta. Para Leplat $(2011$, p.24) o realizador elabora sua própria tarefa em termos de ações a realizar. A elaboração da tarefa redefinida "depende evidentemente da tarefa prescrita, em particular de seu grau de explicitação, mas também das condições próprias ao sujeito (conhecimentos, competências, recursos, etc.) e de condições externas (físicas, técnicas, organizacionais, etc.)".

A tarefa efetiva (ou real) é aquela efetivamente realizada em função das exigências de cada situação singular. "A cada realização da tarefa redefinida corresponde uma tarefa efetiva (ou tarefa real). A tarefa efetiva é a tarefa redefinida realizada. Ela pode ser descrita a partir da observação da atividade" (RABARDEL et al.,1998, p.26).

A atividade pode como a tarefa ser prescrita, esperada, redefinida e efetiva (ou real). Estes conceitos se distinguem na medida em que a tarefa é o que é requerido do indivíduo mais ou menos explicitamente e as condições impostas 
para a sua execução. Enquanto a atividade diz respeito às respostas que o indivíduo põe em prática, o que ele faz realmente para cumprir a tarefa.

A atividade compreende múltiplas dimensões: afetiva, cognitiva, física... Ela pode ser analisada a partir de comportamentos (gestos, posturas, movimentos,...). Verbalizações ligadas diretamente à realização do trabalho ou que a acompanham (reveladoras de situações de conflito, de stress...) e mais geralmente a partir do que é facilmente observável ou que se pode recolher. (RABARDEL et al., 1998, p.27).

Segundo Rogalski (2010) a atividade se trata de um processo, que se desenvolve em uma dada temporalidade, integrando processos físicos (construção de representações mentais, inferências, hipóteses, etc. do lado do tratamento cognitivo da situação, mas também da gestão emocional). Seja esta, em operações de interação do sujeito com objetos ou com outros seres.

A análise da atividade permite compreender os modos de funcionamento do operador face às situações de trabalho, sua maneira de gerir a diversidade e a variabilidade dos elementos da situação que são pertinentes para atingir os objetivos que foram fixados, seu modo de organização (ações, tomadas de informações, gestão do tempo...), assim como as consequências da atividade do operador (RABARDEL et al., 1998, p.28).

Particularmente, em situações institucionais (trabalho, formação), Rogalski (2010, p. 27) aponta que onde "existe um prescritor da tarefa, a atividade é bastante orientada pela realização da tarefa". Neste sentido, a análise da atividade se apoia em uma análise precedente da tarefa. O que nos remete diretamente à situação de um dado estudante-estagiário, quando tem que realizar a docência a fim de satisfazer as condições e orientações do professor-supervisor de estágio numa dada escola. Diante disto, realça-se o nosso interesse em estudar como tem se sobressaído o estudante-estagiário em situação de trabalho (no ensino de matemática), diante das tarefas e atividades prescritas e esperadas por seu professor-supervisor. 


\section{Metodologia}

No $8^{\circ}$ período da licenciatura em matemática (na UFRPE) é previsto que os licenciandos realizem o estágio supervisionado no Ensino Médio (EM), com uma parte deste, reservada à observação de classe e outra à prática de ensino. Desta forma, têm-se aqui, um relato de experiência do acompanhamento do estágio em tela, desenvolvido no semestre letivo de 2016.2 (enquanto professora-orientadora do estágio supervisionado - na universidade) em uma escola pública da rede estadual de Recife- PE.

A abordagem do estudo de caso tratada neste artigo está voltada para a análise clínica da atividade. Nesta perspectiva, o estudo de caso comporta um diálogo com o agente, ou com os agentes, que intervém na situação considerada (LEPLAT, 2008).

Sobre a EELM, esclarecemos que ela tinha uma singular relação com a escola, devido ter sido bolsista do Programa Institucional de Bolsa de Iniciação à Docência (PIBID) do Ministério da Educação, durante um ano e dois meses, no Ensino Fundamental (EF). Entretanto, o trabalho desenvolvido com o professorsupervisor, como dissemos, foi realizado em uma turma do Ensino Médio (EM), para atender à matriz curricular do curso de licenciatura em matemática. $\mathrm{O}$ professor-supervisor tinha formação em licenciatura em matemática e bacharelado em administração. No momento do estudo, ele trabalhava na escola a dois anos e atuava em turmas do EF e do EM. Porém, não havia ainda sido supervisor do estágio da referida estudante.

Especificamente, o estudo foi baseado em 3 etapas desenvolvidas em um período de quatro semanas. A primeira etapa foi centrada no professor-supervisor e em suas tarefas e atividades prescritas e esperadas. A segunda etapa teve foco na "tarefa e atividade redefinida" pela EELM e finalmente, na terceira etapa, ocorreu a análise de como a EELM efetivamente realizou a tarefa, em princípio prescrita pelo professor-supervisor. 
Na primeira etapa, utilizou-se uma entrevista do tipo semiestruturada para interpelar o professor-supervisor sobre o tema da aula a ser trabalhado por EELM. Haja vista, que neste tipo de entrevista "é possível exercer um certo tipo de controle sobre a conversação, embora se permita ao entrevistado alguma liberdade. Ela também oferece uma oportunidade para esclarecer qualquer tipo de resposta quando for necessário" (MOREIRA; CALEFFE, 2006, p.169).

Particularmente, para a análise do trabalho da EELM (segunda etapa) foi utilizada a entrevista semiestruturada e a videogravação das aulas. Em um primeiro momento, por meio da entrevista semiestruturada, buscou-se levantar os recursos utilizados para a preparação da aula e o entendimento da EELM na redefinição do que havia sido prescrito pelo professor-supervisor. Sobre a videogravação, ressaltamos a sua relevância para o uso da técnica de autoconfrontação. Também sublinhamos, que o "vídeo (filmagem) é indicado para estudo de ações humanas complexas difíceis de serem integralmente captadas e descritas por um único observador, minimizando a questão da seletividade do pesquisador" (PINHEIRO, KAKEHASHI; ANGELO, 2005, p.718). Essencialmente, pela possibilidade de se rever várias vezes as imagens gravadas, o que direciona a atenção para aspectos que teriam passado despercebidos, podendo imprimir maior credibilidade ao estudo.

Por fim, em continuidade à análise do trabalho da EELM, na terceira etapa, ocorreu o uso da autoconfrontação. Segundo Clot (2006) a autoconfrontação se insere no seguinte paradigma de pesquisa: o problema não é desenvolver a interpretação do pesquisador, o importante é desenvolver a interpretação dos trabalhadores. Desta forma, a autoconfrontação é vista como um dispositivo pelo qual os trabalhadores "desenvolvem a sua interpretação sobre o trabalho que fazem" (CLOT, 2006, p. 106). Os tipos de autoconfrontação podem ser simples ou cruzada. A autoconfrontação simples envolve sujeito/ pesquisador/imagens; enquanto que a autoconfrontação cruzada envolve dois sujeitos/ pesquisador/imagens do colega (CLOT, 2001). 
$\mathrm{Na}$ autoconfrontação simples, de posse das gravações do pesquisado durante a realização de sua tarefa; o pesquisador:

Seleciona algumas cenas significativas e assiste a elas juntamente com o trabalhador, suscitando nele a descrição do que ele vê no vídeo e propiciando uma relação dialógica com o objeto filmado, com os sujeitos envolvidos na atividade e com o próprio pesquisador. (BRASILEIRO, 2011, p. 211).

Na modalidade de autoconfrontação cruzada:

Há o encontro de dois trabalhadores com o pesquisador. Ambos os trabalhadores, cujas atividades foram filmadas, assistem aos vídeos um do outro e comentam sobre suas ações. Essas sessões devem ser gravadas em áudio ou vídeo pelo pesquisador, que faz perguntas, quando julgar necessário, conduzindo as reflexões e tomadas de consciência sobre o que fazem. (BRASILEIRO, 2011, p. 211).

A autoconfrontação realizada com a EELM foi do tipo simples. Ressaltamos que a autoconfrontação não se constitui um procedimento metodológico totalmente neutro, pois a seleção de imagens também pode ser manipulada pelo pesquisador para a obtenção de certas informações do pesquisado. Haja vista, que na autoconfrontação pesquisador e pesquisador interagem entre si na discussão das imagens.

Sobre a autoconfrontação, dispensou-se o maior tempo de análise, visto que para a melhor compreensão do encadeamento das situações em sala de aula, em um primeiro momento, o pesquisador (professora-orientadora do estágio supervisionado na universidade) assistiu as aulas por completo. De posse de alguns elementos a serem indagados a EELM, foram organizadas duas sessões de autoconfrontação (120min) - para análise das duas aulas ministradas (100min). Esclarecemos que nas sessões de autoconfrontação, à EELM foi dada inteiramente a liberdade de comentar o que ela própria sentiu necessidade de fazê-lo, como veremos a seguir. 


\section{0 trabalho prescrito a EELM pelo professor-supervisor}

Como vimos, do lado do prescritor, duas tarefas se sobressaem: a tarefa prescrita e a tarefa esperada. Neste estudo, dentre outras atividades do estágio supervisionado (observação de classe e prática de ensino), tomou-se como elemento de análise a tarefa prescrita pelo professor-supervisor a EELM: realizar duas aulas sequenciadas para uma turma do $1^{\circ}$ ano do EM, sobre o conteúdo "regra de três composta". Sobre a tarefa esperada, evidenciou-se que o professorsupervisor esperava uma revisão deste conteúdo para as provas finais, dada a proximidade do final do ano letivo. Assim, podemos verificar no currículo da rede de ensino estadual de PE que este conteúdo foi previsto para $01^{\circ}$ bimestre. Portanto, já havia sido trabalhado na referida turma ${ }^{3}$.

No que concerne aos tipos de atividades, prescrita e esperada, pelo professor-supervisor (ao modus operandi de EELM), ele a deixou livre para a escolha dos exercícios que seriam propostos aos estudantes. Segundo EELM, nenhum material de referência foi indicado, como livro didático, uso de projetor ou sites. Mas, como ela já conhecia o contexto da escola e da turma, organizou sua aula, de acordo com o que achou que seria mais adequado.

\section{A redefinição da EELM do trabalho prescrito}

A aula preparada por EELM foi baseada em dois recursos: o site de busca "google" e o site infoescola ${ }^{4}$. Segundo a mesma, ela preparou slides, devido à escola dispor de projetor e porque isto facilitaria a exposição do conteúdo, dos exemplos e exercícios. Na elaboração dos slides ocorreram, sobretudo, recortes do material disponível no "Info Escola". As escolhas efetuadas foram em virtude do seu interesse e do que objetivou para a aula, como descreveremos a seguir.

\footnotetext{
${ }^{3}$ Fonte: http://www.educacao.pe.gov.br/portal/upload/galeria/750/curriculo_matematica_em_2.pdf

${ }^{4}$ Ver: http://www.infoescola.com/matematica/regra-de-tres-simples-e-composta/
} 
A introdução do tema da aula ocorreu por meio de uma breve abordagem histórica (Figura 1). Afirmou a EELM: “_Eu gosto de trabalhar, de começar o assunto com História da Matemática. Eu não sei de tudo, mas pelo menos acho legal de introduzir um pouco do porquê e a época em que surgiu o assunto".

Figura 1 - Introdução do tema da aula

Un Pouco DE Histopa

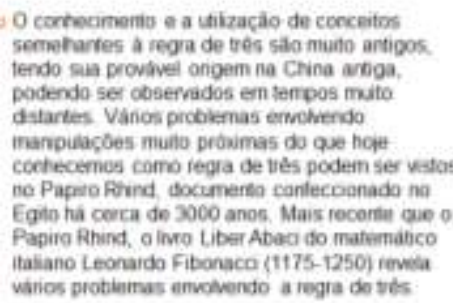

.Fonte: http://www.infoescola.com/matematica/regra-de-tres-simples-e-composta/

Na sequência da aula, a EELM propôs a apresentação de dois exemplos: um de regra de três simples e um de regra de três composta.

Figura 2 - Exemplos sobre regra de três simples e regra de três composta.

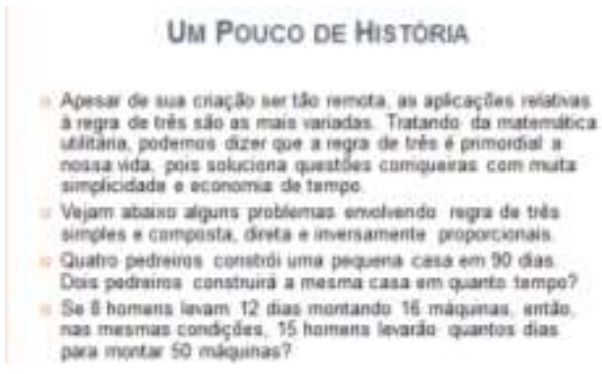

Fonte: http://www.infoescola.com/matematica/regra-de-tres-simples-e-composta/

Sobre o slide apresentado na Figura 2, ao ser questionada por que tratar de regra de três simples, quando a tarefa prescrita pelo professor-supervisor seria uma aula sobre regra de três composta, a EELM afirmou que os estudantes não poderiam compreender "uma sem a outra". Ou seja, a revisão da regra de três simples foi colocada como um pré-requisito para a revisão sobre regra de três composta. O que nos leva à afirmação que isto não foi prescrito pelo professorsupervisor e sim, fez parte, das redefinições da tarefa prescrita pela EELM. Sobre tal fato, como bem coloca Leplat $(1997$, p. 26) "a quem foi confiada a tarefa prescrita, este não é jamais um puro executante desta". 
Outro aspecto evidenciado na autoconfrontação (Figura 3) foi a intenção da EELM de que os estudantes compreendessem a definição de grandezas diretamente e inversamente proporcionais.

Figura 3 - Grandezas diretamente e inversamente proporcionais.
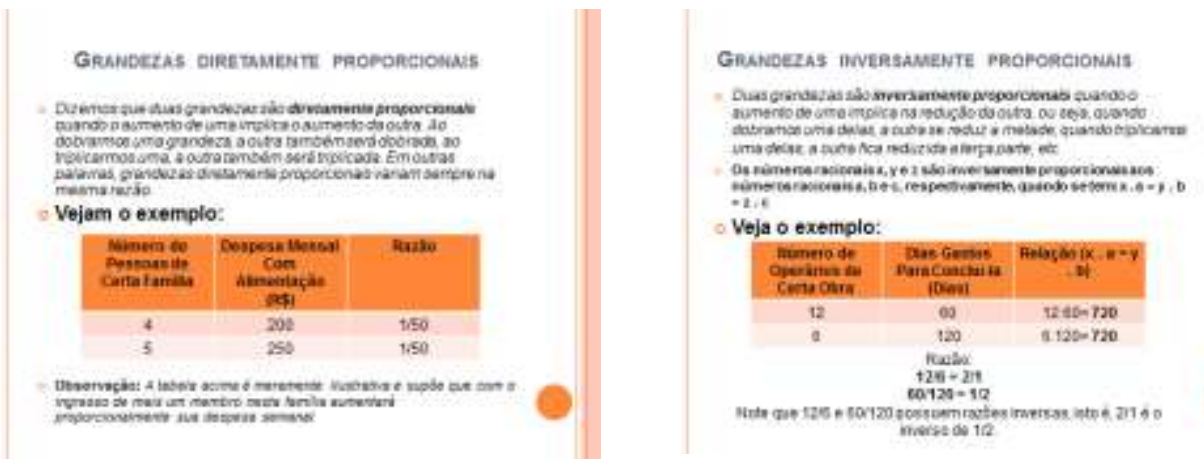

Fonte: http://www.infoescola.com/matematica/regra-de-tres-simples-e-composta/

$\mathrm{Na}$ argumentação da EELM (Figura 3) foi marcante a ideia de comparar as grandezas para os estudantes perceberem a diferença "se quando a medida de uma grandeza diminuía se ocorria isto com a outra. Ou se ocorria que quando uma diminuía a outra aumentava". Na Figura 4, a seguir, buscou-se chamar a atenção dos estudantes para a multiplicação dos "extremos vezes os meios". Segundo a EELM, este foi um aspecto considerado importante para a revisão do conteúdo. Além disto, este material por está disponível no site InfoEscola, foi "fácil copiar e colar". O que nos remete ao fato que um dos elementos de redefinição da tarefa prescrita é a "economia da carga de trabalho" (LEPLAT, 1997).

Figura 4 - Exemplos propostos sobre regra de três simples
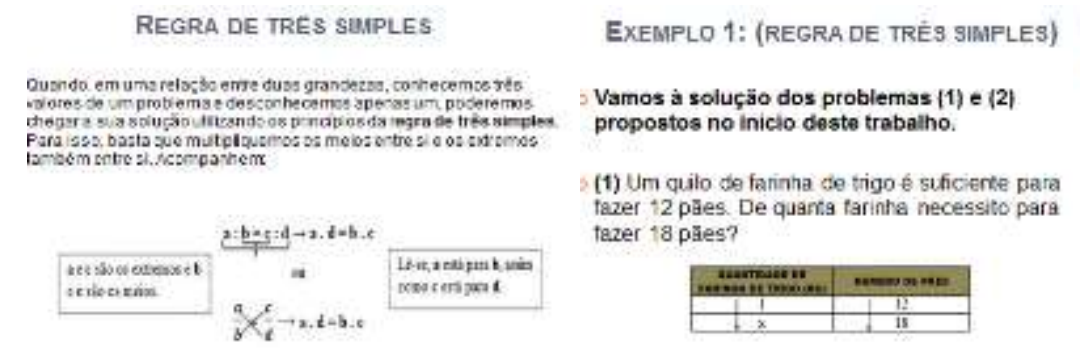

EXEMPLO 2: (REGRA DE TRES SIBPLES)

(2) Quaro gacheros constnem uma pejuene c.ง mrema cata om qantn xemon?

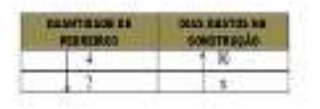

Fonte: http://www.infoescola.com/matemática/regra-de-tres-simples-e-composta/ 
Praticamente a proposição dos exemplos sobre regra de três simples (Figura 4, exemplos 1 e 2) foi pensada a priori para levar os estudantes a distinguirem grandezas inversamente e diretamente proporcionais. Diferentemente, do proposto na Figura 5, cujo objetivo para EELM foi: _"Aqui eu quis mostrar que quando temos mais de duas grandezas a regra de três é chamada de composta".

Figura 5 - Exemplo proposto sobre regra de três composta

REGRA DE TRÉS COMPOSTA

Quando trabaihamos com trés grandezas diveta ou isversarneinte proporcionais e, num delerminado probiema, existem seis valores, dos queis cinco sä́o conhecidos e apenes um desconinecido pode. se enconitrar o valor de incognnta atravis da regra de tres composta.

Vamos à soluçâo dos problemas (3) propostos no inicio deste trabalho.

\section{EXEMPLO 3: (REGRA DE TRÉS COMPOSTA)}

(3) Se 8 homens levam 12 das mantando 16 máquinas entăo, nas mesmas condiçbes. 15

homens levaräo quartos dias para mortar 50 maquinas?

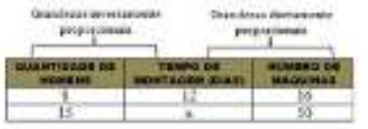

Fonte: http://www.infoescola.com/matemática/regra-de-tres-simples-e-composta/

Em ambos os casos (Figura 4 e Figura 5), os exemplos foram selecionados, por serem considerados "básicos". Ainda que o exemplo sobre regra de três composta, tenha envolvido grandezas inversamente proporcionais; segundo a EELM, "um tipo mais complicado de resolver". De modo que vemos assim, mais exemplos de regra de três simples que composta, em sua elaboração da aula. Sobre isto, a EELM reafirmou: _ "Se era para revisar, então quis assim mostrar do começo, da base". O que nos remete ao fato que o agente-operador define sua própria tarefa a partir da tarefa prescrita e a partir de suas próprias características (LEPLAT, 1997).

A última parte da aula versou sobre três situações-problemas propostas à resolução dos estudantes, selecionadas do ENEM (Figura 6). Sobre isto foi dito: "_O professor trabalhava muito com questões do ENEM. Foi minha primeira experiência de estágio no Ensino Médio, então eu não tinha exercícios já selecionados. Assim, eu coloquei no Google 'questões de regras de três ENEM'. Mas, não lembro mais o site de onde tirei". 
Figura 6 - Situações- problemas propostas à resolução dos estudantes.
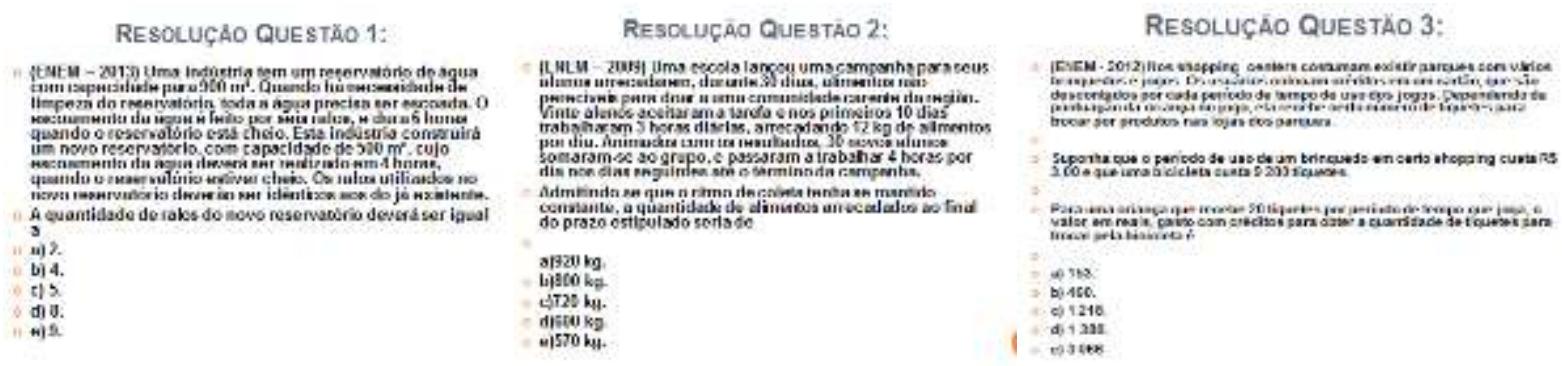

Fonte: www.google.br

Como já dissemos, embora o professor-supervisor não tenha indicado explicitamente a EELM que exercícios deveriam ser utilizados em sua aula. Podemos dizer que o fato dela, em "observação de classe", já ter visto ele propor questões do ENEM, influenciou seu processo de escolha dos exercícios:

- Tinha várias, aí eu peguei aquelas que achei mais interessante. A primeira tem um nível mais imediato. Na segunda, se você não ler a questão não acerta e a terceira, de regra de três simples, eu quis colocar uma mais fácil. Porque no ENEM dificilmente você encontra uma questão de regra de três simples. Quando vi, decidi colocá-la.

Outro aspecto salientado por a EELM no processo de escolha das situações-problemas do ENEM foi: “_Eu respondi e vi a alternativa, aí bateu com a resposta, aí pronto. Eu respondi do meu jeito, que eu gosto de resolver e então me disse: pronto! São estas”. Particularmente, constatamos uma atenção singular sobre o fato dela responder antecipadamente as "questões do ENEM" que seriam propostas aos estudantes. Algo que para ela, já se enraizou em sua prática docente e desta forma, não gostaria de correr o risco de se equivocar no modo de responder um problema na frente dos estudantes. De forma que concordamos com Rogalski (2003) que este é um dos aspectos importantes de redefinição de tarefas prescritas: a tarefa redefinida ocorre antes da tarefa efetiva e como tal, permite fazer representações sobre a ação vindoura.

\section{0 trabalho efetivo da estudante-estagiária em sala de aula}

A propósito dos resultados da autoconfrontação sobre a aula realizada, pomos em relevo que o sujeito submetido a esta técnica deve encontrar-se em 
condições que thes permitam se abrir para si mesmo, "o que ele constata dele mesmo em ação"; bem como "o que ele experimenta como necessidade de recriar como significações, a princípio para si mesmo, em reação a esta constatação" (VIEIRA; FAÏTA, 2003, p. 60). Desta forma, no momento da introdução do tema, ao assistirmos à videogravação, foi percebido que os estudantes se mantiveram apáticos quanto à apresentação dos slides que tratavam da "História da Matemática” (Figura 1). Sobre isto, a EELM, comentou: “_Os estudantes permaneceram calados. Acho que eles desconheciam, não tinham a menor noção do que eu estava abordando. Talvez, por serem estudantes do Ensino Médio, eles gostam mais de exercícios. Este negócio de lúdico, não interessa muito a eles". Visto que o professor-supervisor não tinha a prática de abordar a "História da Matemática". Assim, a EELM se delimitou em "ler os slides" e em não dirigir perguntas aos estudantes; ou seja, ela não explorou, como gostaria, se eles já conheciam ou não a origem dos conteúdos abordados (Figura 1).

No caso dos exemplos apresentados (Figura 2): na primeira situaçãoproblema (de regra de três simples e com grandezas inversamente proporcionais) - 1. "Quatro pedreiros constrói uma pequena casa em 90 dias. Dois pedreiros construirá a mesma casa em quanto tempo?" - foi levantada a questão, no momento da aula, se a situação-problema envolvia grandezas diretas ou inversas e foi proposto que os estudantes a respondessem "de cabeça". Neste caso, os estudantes conseguiram respondê-la rapidamente. Entretanto, os estudantes não conseguiram responder "de cabeça" a outra situação-problema (Figura 2), também envolvendo grandezas inversas, mas de regra de três composta: 2. "Se 8 homens levam 12 dias montando 16 máquinas, então, nas mesmas condições, 15 homens levarão quantos dias para montar 50 máquinas?" - O que levou a EELM afirmar para eles que a responderia "lá na frente". Um comentário sobre os exemplos propostos foi que: “_Eu queria fazer a comparação. Tem questões que podem ser resolvidas rapidamente; "de cabeça", mas com a regra de três composta isto fica mais complicado. Eu queria que eles entendessem isto". 
Embora a EELM tenha se detido a ler os slides (Figura 3), um aspecto de destaque sobre sua explicação foi levar os alunos a entenderem o papel da multiplicação e da divisão quando as grandezas são diretamente ou inversamente proporcionais. Neste caso, ela demonstrou ter ficado contente pelo fato de alguns estudantes terem gostado desta explicação: - "Para resolver uma questão, tem que saber se é inversa ou direta, aí eu trouxe exemplos bem simples. Muitos não sabiam que tinham que dividir na inversa; assim, quando dobramos uma grandeza a outra se reduz na metade".

No momento da resolução dos exemplos no quadro branco (Figura $4 \mathrm{e}$ Figura 5) nos chamou a atenção a contraposição entre "responder de cabeça" as situações-problemas e a minuciosidade em resolver algoritmos simples como, por exemplo: 48 dividido por 24; 4 vezes 90 . Isto nos pareceu uma contradição ao fato de levar os estudantes a responderem "de cabeça" as situações-problemas e desenvolver os algoritmos de tal forma. Sobre isto, a EELM comentou: "_Como sou acostumada a trabalhar com estudantes do $6^{\circ}$ ano, eu procuro detalhar os cálculos. Não sei se no Ensino Médio não precisaria mais fazer assim. Também, não disse poder usar calculadora, pois não tinha nenhuma multiplicação ou divisão tão difícil". Ainda sobre a resolução dos exemplos no quadro branco (Figura 4 e Figura 5) foi percebido a indicação de "letras" referentes às grandezas, quando apenas para a resolução da regra de três composta.

Figura 7 - Resolução dos exemplos com regra de três simples e composta.

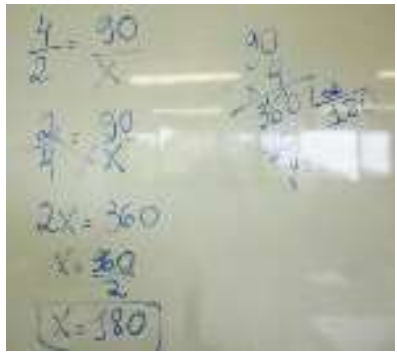

Exemplo 1

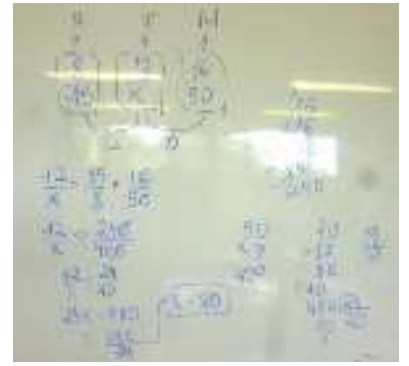

Exemplo 2

Fonte: protocolo de aula da EELM.

Particularmente, no momento da resolução do exemplo 2, sobre regra de três composta (Figura 7), a EELM dirigiu o seguinte comentário aos estudantes: - 
"Eu faço assim, mas cada um tem uma maneira de fazer, né? Eu procuro sempre colocar a letra para referenciar o que eu estou fazendo". Sobre isto, foi dito:

A turma era muito aplicada, mas o problema em resolver regra de três que eu tinha, não faz muito tempo que eu fiz o Ensino Médio, também percebi nos estudantes. Por isso que eu coloco letrinha. O problema é esse: armar a situação, saber onde colocar cada componente, cada grandeza. Porque às vezes na questão se você não souber armar, você vai se confundir.

Neste momento, a EELM comentou que a forma como aprendeu "regra de três" em sua escolaridade básica, estava ensinando para os estudantes. Em consequência de não ter visto na licenciatura em matemática "nenhuma proposta diferente". De certa forma, esta foi uma oportunidade, para que ela voltasse a estudar este conteúdo: "Praticamente, eu estou como se eu estivesse explicando para mim mesma. Eu me senti assim". O que nos revela como a autoconfrontação se baseia na organização de uma atividade dialógica plena de dissonâncias: atividade que vai se dar em um diálogo interior do sujeito consigo mesmo. Particularmente, a oportunidade desse diálogo interior decorre de quando o sujeito é confrontado ao vídeo de sua atividade realizada (ROGER, 2013).

No momento da proposição aos estudantes das situações-problemas do ENEM a serem respondidas (Figura 6), além destas estarem expostas no projetor, houve a sua distribuição impressa. Com base em Rogalski (2003) ressaltamos que na medida em que um dado professor prescreve uma tarefa aos seus estudantes, este tem suas próprias expectativas, o que nos remete às tarefas prescritas e esperadas (da parte da EELM aos estudantes da turma em tela). Desta forma, se por uma parte, tivemos o movimento de observar a tarefa prescrita a EELM pelo professor-supervisor de estágio; por outra parte, as tarefas prescritas por EELM aos estudantes, no momento da aula, também fizeram parte do repertório da análise de seu trabalho efetivo.

Mediante o que sugere Rogalski (2003, p. 354) "a tarefa esperada pelo professor deve ser inferida pela regulação da atividade dos estudantes individuais e da classe". Uma via de acesso a estas informações são "os traços de realização da tarefa, os observáveis no curso de sua realização". Desta forma, para cada 
uma das situações-problemas (do ENEM) buscamos levantar quais as expectativas da EELM sobre a resolução dos estudantes e o que foi efetivamente realizado por eles, a partir de suas próprias constatações.

Sobre a primeira situação-problema (Figura 8), a EELM, comentou: "_ $A$ primeira questão é bem mais simples que a segunda". A maioria deles conseguiu respondê-la. A dificuldade maior foi armar; saber quais valores das grandezas deveriam ser invertidos. Isto já era uma dificuldade bem prevista”.

Figura 8 - Resolução da 1ํㅗㄹ situação-problema proposta à resolução dos estudantes.

1.(ENEM, 2013).Uma indústria tem um reservatório de água com capacidade para $900 \mathrm{~m}^{3}$. Quando há necessidade de limpeza do reservatório, toda a água precisa ser escoada. O escoamento da água é feito por seis ralos, e dura 6 horas quando o reservatório está cheio. Esta indústria construirá um novo reservatório, com capacidade de $500 \mathrm{~m}^{3}$, cujo escoamento da água deverá ser realizado em 4 horas, quando o reservatório estiver cheio. Os ralos utilizados no novo reservatório deverão ser idênticos aos do já existente.

$\begin{array}{lllll}\text { a) } 2 & \text { b) } 4 & \text { c) } 5 & \text { d) } 8 & \text { e) } 9\end{array}$

Fonte: protocolo de videogravação da aula da EELM.

Sobre a segunda situação-problema foi dito:

- A segunda questão era diferente, porque exigia uma atenção a mais deles. Podia-se chegar a uma resposta que estava dentre as alternativas. O que faria eles errarem. Neste caso, tinha que se fazer outro cálculo para chegar à resposta correta. Isto também acontecia na terceira questão.

Já no primeiro instante da apresentação da segunda situação-problema (Figura 9) foi anunciado um brinde para quem a respondesse mais rápido. Sobre o porquê desta ação foi colocado: “_Por esta questão ter 4 grandezas poderia ser mais difícil, assustaria; mas por outro lado, todas as grandezas eram diretamente proporcionais o que facilitaria a compreensão". No entanto, a atenção maior esperada para a segunda situação-problema esteve voltada para: “_ Esta tem a alternativa com '800', então, alguns pensaram ter encontrado a resposta correta. Alguns chegaram a esta resposta e erraram, porque a resposta correta é '920'. Eles tinham que ter lido melhor o problema, eu já previa esta dificuldade”. 
Figura 9 - Resolução da $2^{\text {a }}$ situação - problema proposta à resolução dos estudantes.

2. (ENEM, 2009). Uma escola lançou uma campanha para seus alunos arrecadarem, durante 30 dias, alimentos não perecíveis para doar a uma comunidade carente da região. Vinte alunos aceitaram a tarefa e nos primeiros 10 dias trabalharam 3 horas diárias, arrecadando $12 \mathrm{~kg}$ de alimentos por dia. Animados com os resultados, 30 novos alunos somaram-se ao grupo, e passaram a trabalhar 4 horas por dia nos dias seguintes até o término da campanha. Admitindo-se que o ritmo de coleta tenha se mantido constante, a quantidade de alimentos arrecadados ao final do prazo estipulado seria de:
a) $920 \mathrm{~kg} \mathrm{b)} 800 \mathrm{~kg}$
c) $720 \mathrm{~kg}$
d) $600 \mathrm{~kg}$
e) 570 $\mathrm{kg}$

Fonte: protocolo de videogravação da aula da EELM.

Ao assistir as cenas de sua aula, no momento da resolução da segunda situação-problema, a EELM comentou: _ "Eu não gostei do que aconteceu; pois assim que um estudante conseguiu encontrar a resposta correta, eu entreguei o brinde e os outros ficaram desmotivados. Vendo agora melhor, não acho que isto foi uma boa estratégia". Isto nos remete ao fato que por meio da autoconfrontação, é comum emergirem surpresas, por vezes muito significativas diante do que foi feito efetivamente com relação ao que se acreditava ter sido feito, o que incita a reflexão por parte de quem se vê no vídeo (ROGER, 2013).

Sobre a terceira situação-problema (Figura 10) a EELM afirmou: _ "Esta também precisa interpretar, tem que ler novamente a resposta e pensar se está correta. Pois a resposta certa é "1.380" e alguns responderam ou já achavam que a resposta seria "460". Eu já tinha chamado a atenção deles quando expliquei a 'segunda questão'. Mas mesmo assim ainda erraram." 
Figura 10 - Resolução da 3ํㅗㄹ situação-problema proposta à resolução dos estudantes.

3.Nos shopping centers costumam existir parques com vários brinquedos e jogos. Os usuários colocam créditos em um cartão, que são descontados por cada período de tempo de uso dos jogos. Dependendo da pontuação da criança no jogo, ela recebe um certo número de tíquetes para trocar por produtos nas lojas dos parques. Suponha que o período de uso de um brinquedo em certo shopping custa $R \$ 3,00$ e que uma bicicleta custa 9.200 tíquetes. Para uma criança que recebe 20 tíquetes por período de tempo que joga, o valor, em reais, gasto com créditos para obter a quantidade de tíquetes para trocar pela bicicleta é

$\begin{array}{lllll}\text { a) } 153 & \text { b) } 460 & \text { c) } 1.218 & \text { d) } 1.380 & \text { e) } 3.066\end{array}$

Fonte: protocolo de videogravação da aula da EELM.

Levando-se em conta a aula realizada, ao perguntarmos a EELM se esta teria feita uma aula diferente se estivesse no lugar no professor-supervisor, a mesma afirmou: _ "Faria sim! Eu ainda trabalharia mais regra de três. Eu iria trabalhar situações mais simples. Não estas do ENEM. Pois os estudantes ainda têm muita dificuldade". Temos assim, como já mencionamos, indícios de que em situação institucional (trabalho, formação), onde existe um prescritor da tarefa, a atividade é bastante orientada pela realização da tarefa prescrita. E, convém não perdermos de vista as tarefas redefinidas e efetivas por parte de quem as executa. Haja vista, a forma como a EELM, enfim, se posicionou para atender a tarefa prescrita pelo professor-supervisor (revisar o tema regra de três composta) - "Eu fiz o meu possível, do meu jeito, sempre pensando no que o professor queria; mas, fiz do meu jeito e ele disse que gostou de minha aula”.

\section{Considerações finais}

Este estudo trilhou o objetivo de analisar a passagem do trabalho prescrito sobre uma aula de "regra de três composta", por um professor-supervisor de estágio ao trabalho efetivo de uma estudante-estagiária da licenciatura em 
matemática. Nesta direção, sublinhamos que o trabalho prescrito e o trabalho efetivo são analisados notadamente em termos das tarefas e das atividades.

Diante dos resultados do estudo, a propósito das atividades da EELM na elaboração e implementação da aula sobre "Regra de Trës Composta" (recursos utilizados; expectativas antes da aula; reflexão sobre suas próprias ações durante e depois da aula, etc.); ressaltamos o fato que a tarefa efetiva, pode se distanciar da tarefa prescrita "porque falta mobilidade ao sujeito para se engajar na ação esperada, ou porque ele não tem as competências necessárias para a realizar, ou porque ele construiu uma representação inapropriada" (ROGALSKI, 2010, p. 26). Leplat (2000) coloca que a tarefa efetiva depende do agente (condições internas) que a executa e da tarefa (finalidade (s), condições externas: técnicas, organizacionais, sociais, etc.). Para ambos os autores, as consequências da atividade efetiva/tarefa efetiva agem retroativamente sobre a tarefa prescrita, em função notadamente da adequação aos objetivos perseguidos pelo realizador de uma parte, e de outra, fixados pelo prescritor.

Ao final deste estudo, têm-se mais inquietações do que respostas sobre como o estudante-estagiário se sobressai em situação de trabalho (no ensino de matemática), diante das tarefas e atividades prescritas e esperadas por seu professor-supervisor na escola-campo de estágio. Dito isto, pensamos que as relações no estágio supervisionado entre professor-supervisor, professororientador e estudantes de licenciatura se apresentam como um campo que suscita diversas investigações. Como nos sugere Leplat (1997, p.27): "sempre há implícitos na tarefa prescrita". Assim, registramos a limitação deste estudo ter sido mais voltado à análise da aula da EELM pela autoconfrontação simples. Uma autoconfrontação cruzada (com o professor-supervisor) poderia tê-lo enriquecido. Grosso modo, esperamos que a análise aqui empreendida sobre as práticas no estágio supervisionado suscite novas pesquisas sobre a formação inicial docente para o ensino de matemática. 


\section{Referências}

BRASILEIRO, Ada Magaly Matias. A autoconfrontação simples aplicada à formação de docentes em situação de trabalho. Scripta, Belo Horizonte, v. 15, n. 28, p. 205-224, 2011.

CLOT, Yves et al. Entretien en autoconfrontation croisée: une méthode em clinique de l'activité. Éducation Permanente, Paris, n. 146, p. 17-25, 2001.

CLOT, Yves. Entrevista: Yves Clot. Cadernos de Psicologia Social do Trabalho, São Paulo, v. 9, n. 2, p. 99-107, 2006.

MOREIRA, Herivelto; CALEFFE, Luis Gonzaga. Metodologia da pesquisa para o professor pesquisador. Rio de Janeiro: DP\&A, 2006.

PINHEIRO, Eliana Moreira; KAKEHASHI, Tereza Yoshiko; ANGELO, Margareth. O uso de filmagem em pesquisas qualitativas. Rev Latino-am Enfermagem, Ribeirão Preto, v. 13, n. 5, p.717-722, set.- out. 2005.

RABARDEL, Pierre et al. Ergonomie: concepts et méthodes. Toulouse: Octarès Éditions, 1998.

ROGALSKI, Janine. Y a-t-il um pilote dans la classe? Une analyse de l'activité de l'enseignant commme gestion d'un environnement dynamique ouvert. Recherches en Didactique des Mathématiques, Paris, v. 23, n. 3, p. 343-388, 2003.

ROGALSKI, Janine. Le cadre général de la théorie de l'activité : ume perspective de psychologie ergonomique. In: VANDEBROUCK, F. (Coord.). La classe de mathématiques: activités des élèves et pratiques des enseignants.2. ed. Toulouse: Octarès Éditions, 2010.

ROGER, Jean-Luc. Metodologia e métodos de análise em clínica da atividade. Cadernos de Psicologia Social do Trabalho, São Paulo, v. 16, p. 111-120, 2013.

LEPLAT, Jacques. Mélanges ergonomiques : activité, compétence, erreur. Toulouse : Octares Éditions, 2011.

LEPLAT, Jacques. Repères pour l'analyse de l'activité en ergonomie. Paris: Presses Universitaires de France, 2008.

LEPLAT, Jacques. L'analyse psychologique de l'activité en ergonomie : aperçu sur son évolution, ses modèles et ses méthodes. Toulouse: Octarès Éditions, 2010.

LEPLAT, Jacques. Regards sur l'activité en situation de travail : contribution à la psychologie ergonomique. Paris: Presses Universitaires de France, 1997.

TARDIF, Maurice. LESSARD, Claude. O trabalho docente: elementos para uma teoria da docência como profissão de interações humanas. 3. ed. Petrópolis: Vozes, 2007. 
DOI: http://dx.doi.org/10.5965/2357724X05092017101

VIEIRA, Marcos; FAÏTA, Daniel. Quando os outros olham outros de si mesmo: reflexões metodológicas sobre a autoconfrontação cruzada. Polifonia, Cuiabá, n. 7, p. 27-65, 2003. 